\title{
Catalytic Behaviors of Expansible Graphite in the Synthesis of Butyl Acetate
}

\author{
XIU-YAN PANG \\ College of Chemistry and Environmental Science \\ Hebei University, Baoding 071002, China \\ pxy833@163.com（X.Y. Pang）
}

Received 18 August 2011; Accepted 4 October 2011

\begin{abstract}
The catalysis of expandable graphite EG for esterification has been studied. EG was prepared with $\mathrm{KMnO}_{4}$ as oxidant and $\mathrm{H}_{2} \mathrm{SO}_{4}$ as inserting reagent. Eexpanded volume, $\mathrm{x}$-ray diffraction and energy dispersive analysis for EG were carried, and its catalytic activity was detected in the reaction of acetic acid with butanol. Influence of mole ratio of butanol and acetic acid, dosage of EG on ester yield were optimumed single factor experiments. The suitable esterification condition is: molar ratio of butanol to acetic acid keeps 1.6:1.0, mass of EG keeps 9.0\% of the total mass of reactants; reaction keeping up $1.0 \mathrm{~h}$ at the boling point, and esterification rate of $98.2 \%$ can be achieved. The reuse ester yield is $86.6 \%$ for first reuse and $61.2 \%$ for the second reuse.
\end{abstract}

Keywords: Expandable graphite, Butyl acetate, Catalytic activity, Reuse.

\section{Introduction}

Expandable graphite EG is a kind of new material which is prepared through intercalation reaction of non-carbon substance such as $\mathrm{H}_{2} \mathrm{SO}_{4}$ under the condition of chemical or electric chemistry oxidation ${ }^{1,2}$. Its is normally used as sealing material and adsorbent of oil after being expanded under high temperature ${ }^{3,4}$. At the same time, EG can be used as solid super acid catalyst in acylation reaction ${ }^{5,6}$.

Butyl acetate is a common industrial product, it was widely used in the manufacture of food, cosmetic, lacquer, leather, flavoring extract and pharmaceutical industries. In the synthesis of butyl acetate, $\mathrm{H}_{2} \mathrm{SO}_{4}$ is the traditionary catalyst and the use of $\mathrm{H}_{2} \mathrm{SO}_{4}$ often causes problems such as equipment corrosion and environment pollution. Now, the tested replacers are Solid Supper-acid such as $\mathrm{SO}_{4}{ }^{2-}-\mathrm{ZrO}_{2} / \mathrm{TiO}_{2}$, inorganic salt such as $\mathrm{FeCl}_{3} \cdot 6 \mathrm{H}_{2} \mathrm{O}$, $\mathrm{Fe}\left(\mathrm{SO}_{4}\right)_{3} \cdot \mathrm{XH}_{2} \mathrm{O}, \mathrm{CuCl}_{2} \cdot 2 \mathrm{H}_{2} \mathrm{O}, \mathrm{NaHSO}_{4} \cdot \mathrm{H}_{2} \mathrm{O}, \mathrm{TiSO}_{4}, \mathrm{SnCl}_{4} \cdot 5 \mathrm{H}_{2} \mathrm{O}$, enzyme such as lipase, supported catalysts such as $\mathrm{NaY}$ molecular sieve supported organophosphonic acid (PA/NaY) and so $\mathrm{on}^{7-10}$. But some shortcomings limit theirs application in industry such as low yield of ester (among 70\% 96\%), long reaction time or high cost in catalyst preparation.

EG has the advantages of being easy prepared, lower cost, easy dispersed and recycled. Base on this reason, EG was firstly prepared with $\mathrm{KMnO}_{4}$ as oxidant and $\mathrm{H}_{2} \mathrm{SO}_{4}$ as inserting 
reagent and then its catalysis for esterification between acetic acid and butanol was studied. The influences of catalyst amount, materials ratio on ester yield were investigated.

\section{Experimental}

SX3-4-13 Muffle furnace (Tientsin, precision of temperature $\pm 0.1 \%-0.4 \%{ }^{\circ} \mathrm{C}$ ), WAY refractor (Shanghai, China), Y-4Q X-ray diffractometer (Dandong, China), Energy dispersive spectrum instrument EDS (Thermo NORAN Vantage DIS ) and FTS-40 Fourier transform infra-red spectrometer (America Biorad) were used in this experiment.

Natural graphite (C, 5092) was provided by Action Carbon CO. LTD, Baoding, China. Acetic acid, butanol, $\mathrm{H}_{2} \mathrm{SO}_{4}(96 \%), \mathrm{KMnO}_{4}, \mathrm{Na}_{2} \mathrm{CO}_{3}, \mathrm{CaCl}_{2}, \mathrm{NaCl}$ are all analytical reagents.

\section{Preparation of EG}

At $30^{\circ} \mathrm{C}$, $3.0 \mathrm{~g}$ of natural graphite is mixed with $13.0 \mathrm{~mL}$ of $\mathrm{H}_{2} \mathrm{SO}_{4}$ (mass concentration $75 \%$ ) and $0.45 \mathrm{~g} \mathrm{KMnO}_{4}$ in a $250 \mathrm{~mL}$ beaker. After $30 \mathrm{~min}$, product is washed with deionized water until $\mathrm{pH}$ reaches to $6.0 \sim 7.0$, and then diped in de-ionized water for $2.0 \mathrm{~h}$. Through filtration and dryness at $75 \sim 80^{\circ} \mathrm{C}$ for about $3 \mathrm{~h}$, EG is gained.

\section{Character of EG}

\section{Expanded Volume (EV) of EG}

$\mathrm{EV}$ is an important factor to judge of the intercalation reaction of $\mathrm{H}_{2} \mathrm{SO}_{4}$ into graphite. $0.300 \mathrm{~g} \mathrm{EG}$ is expanded instantly at $900^{\circ} \mathrm{C}$ and turn into expanded graphite and the volume of product is detected with a measuring cup. EV is defined as the volume of expanded graphite corresponding to $1.0 \mathrm{~g}$ of $\mathrm{EG}$, written as $\mathrm{mL} / \mathrm{g}$ and it is detected as $400 \mathrm{~mL} / \mathrm{g}$.

\section{$X$-ray Spectrum of Material Graphite and EG}

Analysis of XRD for material graphite and EG were carried out. Two characteristic diffractive peaks with interplanar crystal spacing of $3.34 \AA$ and $1.67 \AA$ are observed in the spectrum of material graphite (Figure 1). In the XRD analysis of EG (Figure 2), the interplanar crystal spacing change $3.34 \AA$ to $3.42 \AA$, it shows the layer space is bigger than the material graphite and new substance has inserted into samdwich. The lager EV expandable graphite possessed, the higher dosage of $\mathrm{H}_{2} \mathrm{SO}_{4}$ it would hold ${ }^{11}$.

\section{EDS Analysis of EG}

Figure 3 and 4 are results of EDS for material graphite and EG. It gives a relative higher intensity of $\mathrm{S}$ element in EG' EDS than that of material graphite, which testifies the intercalaction of $\mathrm{H}_{2} \mathrm{SO}_{4}{ }^{11}$.

\section{Preparation of Butyl Acetate}

With a definite mole ratio, acetic acid and butanol are added into the reactor appending stirrer and water segregator. Reaction lasts a certain time under the catalysis of EG. Then the 
products are filtrated under vacuum, washed with saturated solution of $\mathrm{Na}_{2} \mathrm{CO}_{3}, \mathrm{CaCl}_{2}$, and $\mathrm{NaCl}$, respectively. The upper layer solution is distilled under air pressure, the fraction corresponding to $120 \sim 124^{\circ} \mathrm{C}$ is collected. Then distillate is analysed with refractor and IR, respectively. The collected product in distillation is colorless, transparent and with the taste of fruit. Its refractive index is detected as 1.394 at $25^{\circ} \mathrm{C}$ (reported value $1.391 \sim 1.395$ ). In the IR spectrum analysis of the distillate, characteristic peak of $\mathrm{C}-\mathrm{H}\left(1235.94 \mathrm{~cm}^{-1}\right), \mathrm{C}=\mathrm{O}$ $\left(1639.34 \mathrm{~cm}^{-1}\right)$ and C-C-C $(=\mathrm{O})-\mathrm{O}\left(1619.08 \mathrm{~cm}^{-1}\right)$ are all observed. Yield of butyl acetate is calculated according to equation (1).

Yield $\%=\left(\mathrm{m}_{\text {obtained butyl acetate }} / \mathrm{m}_{\text {theory butyl acetate }}\right) * 100 \%$

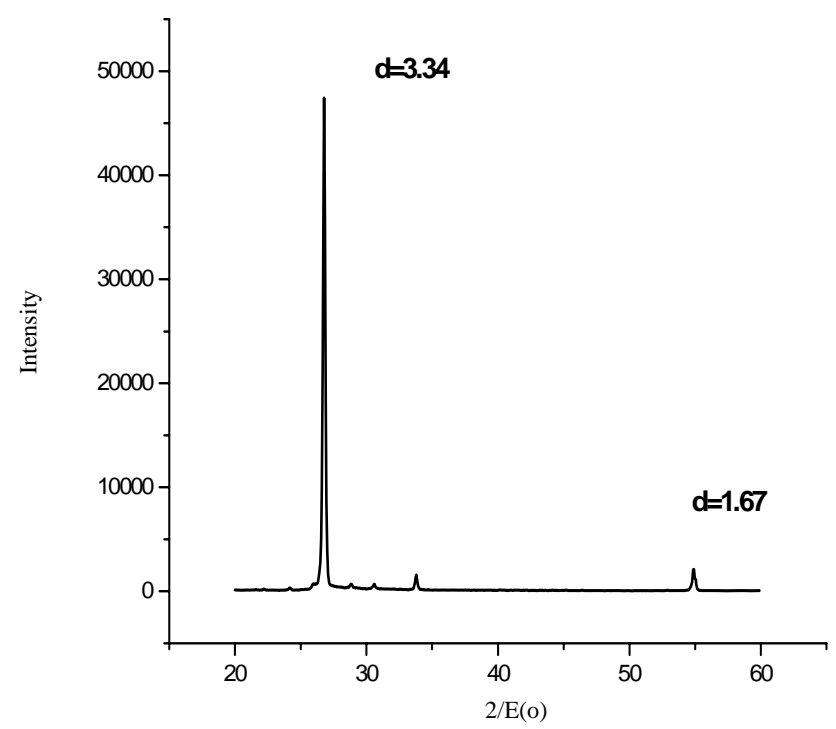

Figure 1. XRD of material graphite.

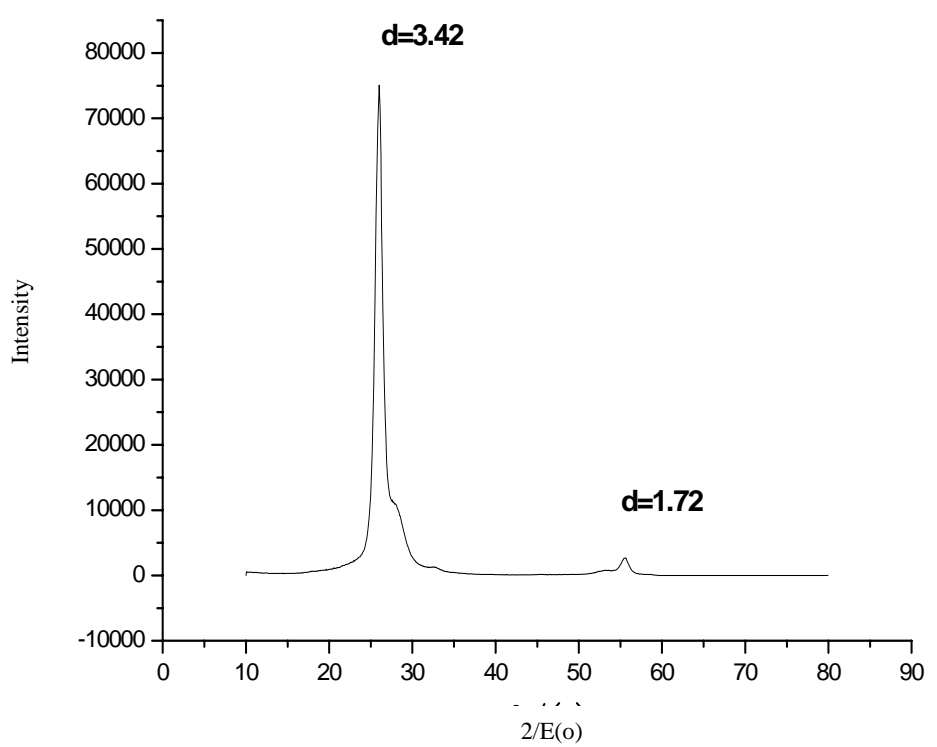

Figure 2. XRD of EG. 


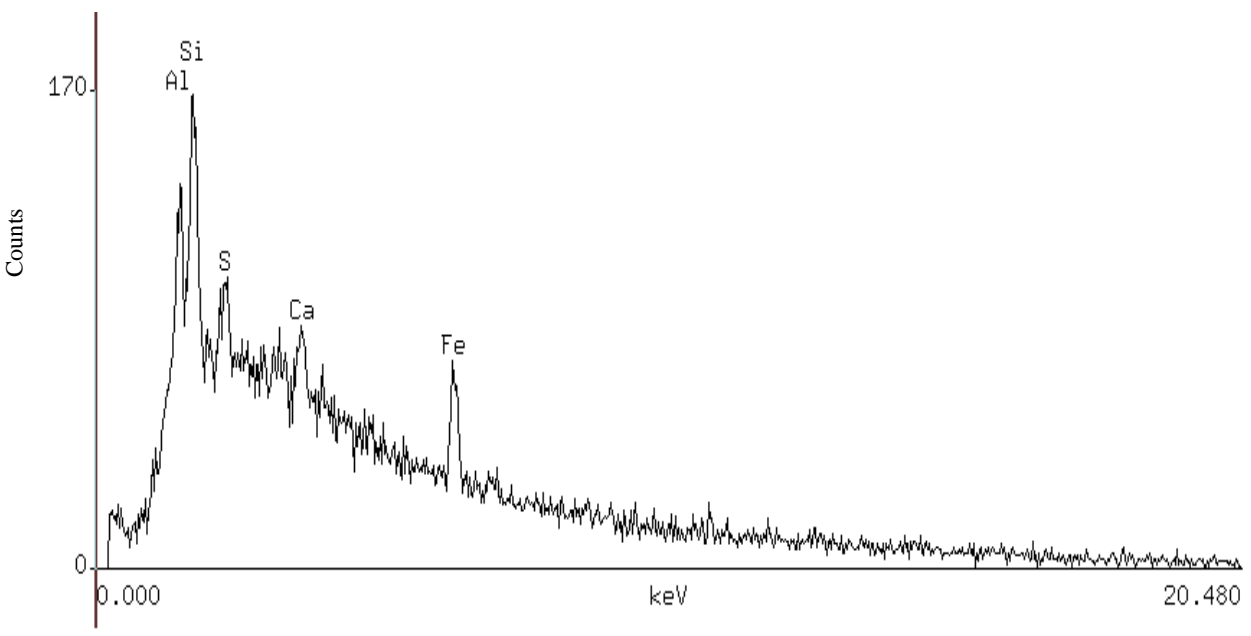

Figure 3. EDS of material graphite.

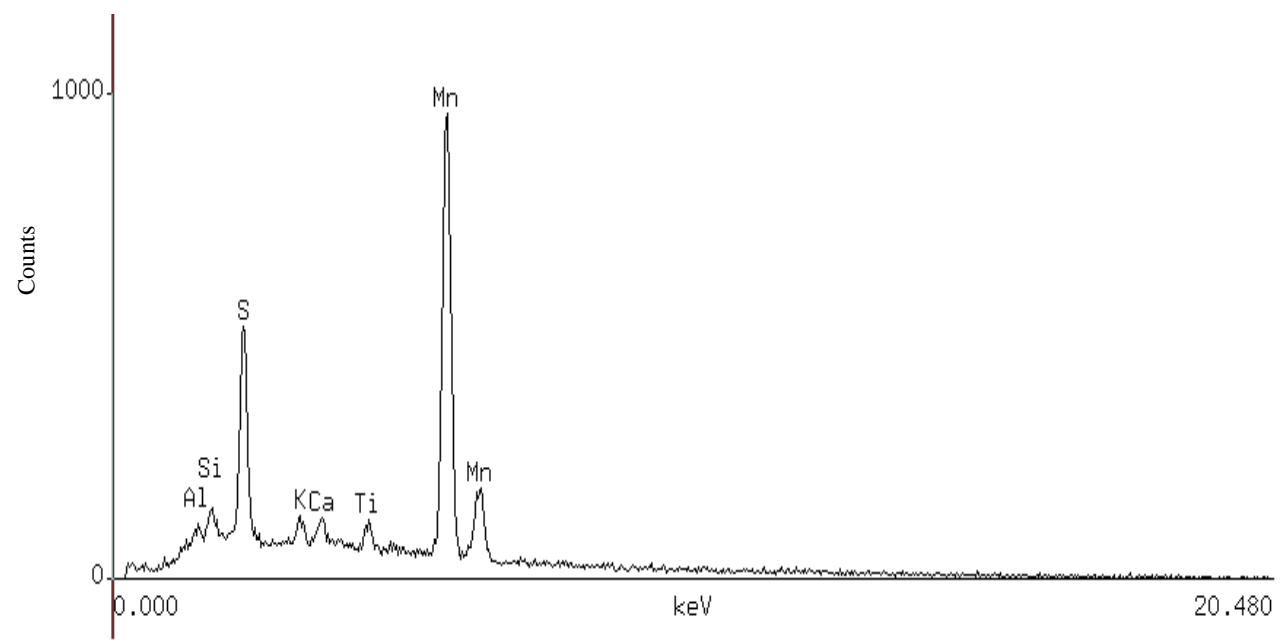

Figure 4. EDS of EG.

\section{Results and Discussion}

\section{Optimizing of Esterification Reaction}

\section{Influence of Mole Ratio between Butanol and Acetic Acid on Yield}

In esterification, mole ratio of reactants is the most important influence factor on ester yield. To find the feasible ratio, butanol to acetic acid of $0.8: 1.0 \sim 1.8: 1.0$ is tested with the reaction keeping at boiling state, mass of EG setting as $7.5 \%$ of the total mass of reactants, and reaction stopped until no water separated. As showed in Figure 5, the reaction gets the lowest yield at ratio of 1.0: 1.0 and it increase with the dosage increase of butanol or acetic acid. Excessive butanol is used in view of its function of acting as water-carrying agent. Ester yield increases with the increase of propanol when the ratio is among 1.0: $1.0 \sim 1.6$ : 1.0 , beyond this value, it began to decrease. To high dosage of butanol would increase the wastage of heat and debase the purity of product. So the $n$ (butanol) $: n($ acetic acid $)=1.6: 1.0$ should be used. 


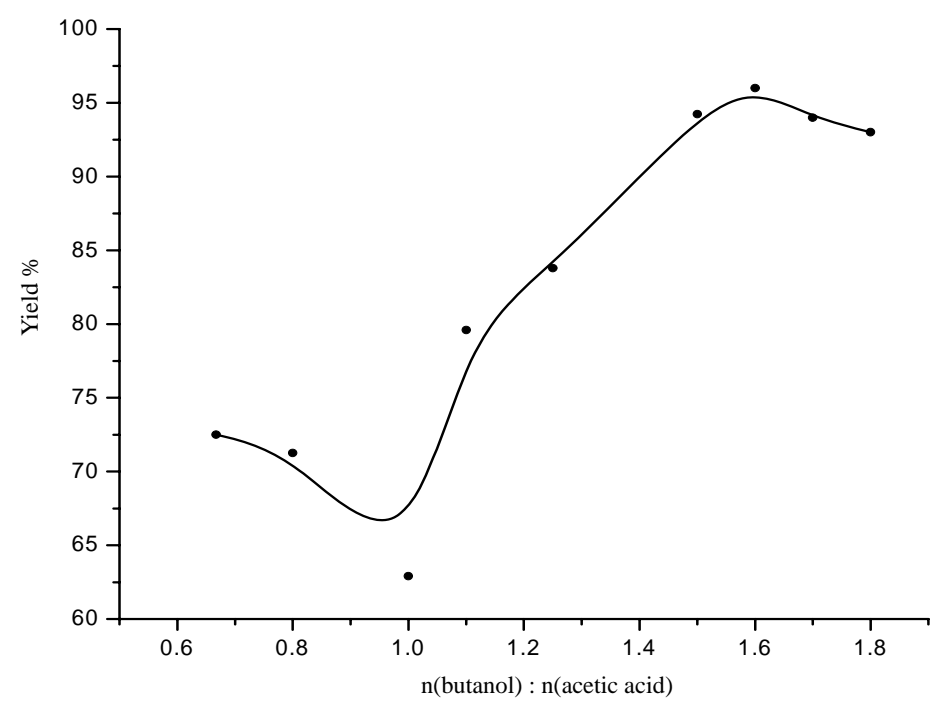

Figure 5. Influence of butanol/acid mole ratio on ester yield.

Condition: mass of EG is $7.5 \%$ of the total mass of reactants, reaction keeping at boiling state until no water separated.

\section{Influence of Catalyst Dosage on Yield}

As tested in single factor experiments, the reaction gets a maximal ester yield at $9.0 \%$ when the mass of EG is changed in the range of $6.0 \% \sim 10.0 \%$ of the total mass of reactants (showed in Figure 6). Too high EG dosage would lead side reaction, and increase loss of product during filtration separation of EG.

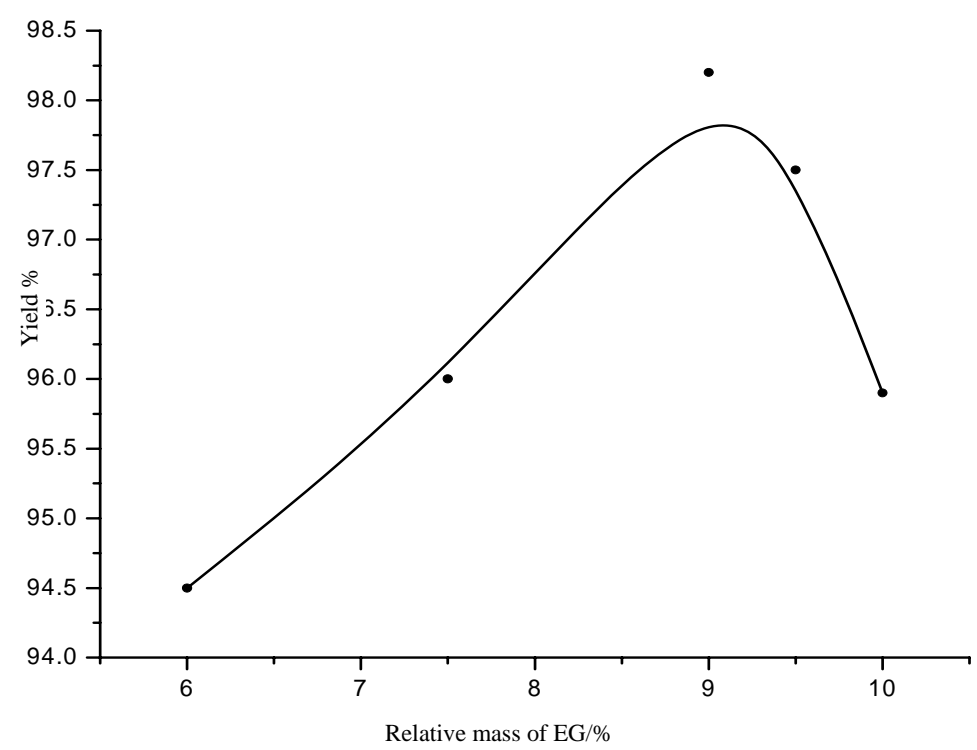

Figure 6. Influence of EG mass on ester yield. 
(Condition: ratio of $n$ (butanol) $: n$ (acetic acid) equals $1.6: 1.0$, reaction keeping at boiling state until no water separated).

\section{Selection of Water-Carrying Agent}

Function of water-carrying agent is increase the yield of ester through formation of azeotrope with water, which is in favor of the separation of water. The normally used water-carrying agent is cyclohexane and the boiling point of azeotrope composed $8.4 \%$ water and $91.6 \%$ yclohexane is $68.95{ }^{\circ} \mathrm{C}^{12}$. Too low temperature would decrease reaction rate, and at the same time, the addition of too many of cyclohexane would consume a large amount of heat energy during distillation and separation of product. When $n$ (butanol) $: n$ (acetic acid) $=1.6: 1.0$ is adopted, the superfluous butanol would play the role of carrying water. So no additional dehydrolyzing agent is needed.

\section{Feasible Condition to Prepare Butyl Acetate with EG as Catalyst}

Base on the above experiments, the feasible conditions to get butyl acetate are gained as: $n($ butanol $): n$ (acetic acid $)=1.6: 1.0, w($ catalyst with a $\mathrm{EV}$ of $400 \mathrm{~mL} / \mathrm{g})=9.0 \%$ total amount of reactants and reaction keeps at boiling point until no water separated. Yield of butyl acetate can reach $98.2 \%$.

\section{Reuse of EG}

EG shows better activity for the aimed esterification reaction, so its reuse is carried out under the mentioned optimum esterification condition. Before reuse, the catalyst is treated with filtration and dryness under $75 \sim 80^{\circ} \mathrm{C}$. Its reuse rates are $86.6 \%$ for the first time and $61.2 \%$ for the second time. The fall of reuse rate may be caused by the change of brim structure of EG grain, which may increase the mass transfer resistance. But the EV of this reused catalyst ishas no obvious change (The EV is $400 \mathrm{~mL} / \mathrm{g}$ before used in the reaction, and it's $398 \mathrm{~mL} / \mathrm{g}$ after the catalysis).

\section{Conclusion}

The feasible conditions to prepare butyl acetate with EG as catalyst are gained as: $n$ (butanol): $n$ (acetic acid) $=1.6: 1.0, w($ EG with a $\mathrm{EV}$ of $400 \mathrm{~mL} / \mathrm{g})=9.0 \%$ of the total amount of reactants, reaction keeps at boiling point until no water separated. Yield of butyl acetate can reach $98.2 \%$.

EG possesses higher catalytic activity in esterification of butanol with acetic acid and it could be used as polyphase catalyst in organic reaction with proton transfer.

\section{Acknowledgment}

This study was supported by Doctor Foundation of Hebei province Education Office (China, No.B2004402) and Doctor Foundation of Hebei University. We gratefully acknowledge their support during the study.

\section{Reference}

1. Xue M L, Yu Y L, Ren Z H and Zhang J S, Fine Chem., 2002, 19, 567.

2. Chen X L, Song K M and Li J H, Carbon, 1996, 34, 1599.

3. Zhao Z P, China Non-metallic Mining Ind Herald., 2003, 1, 7.

4. Beata T, Antoni W M, Ryszard J K N and Michio I, Spill Sci Tech Bull., 2003, 8, 569. 
5. $\quad$ Jin T S, Ma Y R and Li T S, Indian J Chem., 1999, B38, 109.

6. Li Y F, Wang Z Y, Lai Q and Liu G Q, Ind Catal., 2007, 15, 24.

7. Zhou Y and Jiang D H, Hebei Chem Eng Ind., 2008, 31, 27.

8. $\quad$ Du Z L and Liu C F, J Hefei Teachers College., 2008, 26, 79.

9. Salah R B, Ghamghui H, Miled N, Mejdoub H and Gargouri Y, J Biosci Bioeng., 2007, 103, 368.

10. Chen L, Yin P, Hu Y C, Zhang J, Yang L X and Jiang W, J. Taiwan Institute of Chem Eng., 2011, 42, 768.

11. Thirumal M, Khastgir D and Singha N K, J Appl Poly Sci., 2008, 110, 2586.

12. Cheng L X, Solvent Handbook, $3^{\text {th }}$ Edn., Beijing: Chemical Industry Publishing House, 2002, 17-19. 


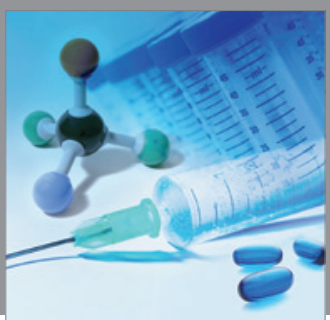

International Journal of

Medicinal Chemistry

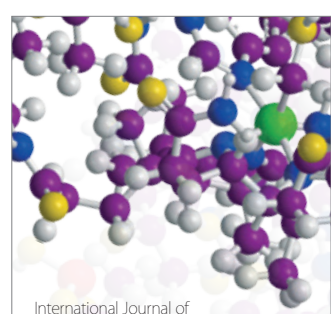

Carbohydrate Chemistry

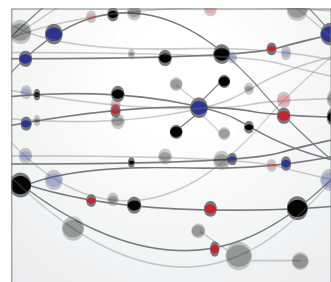

The Scientific World Journal
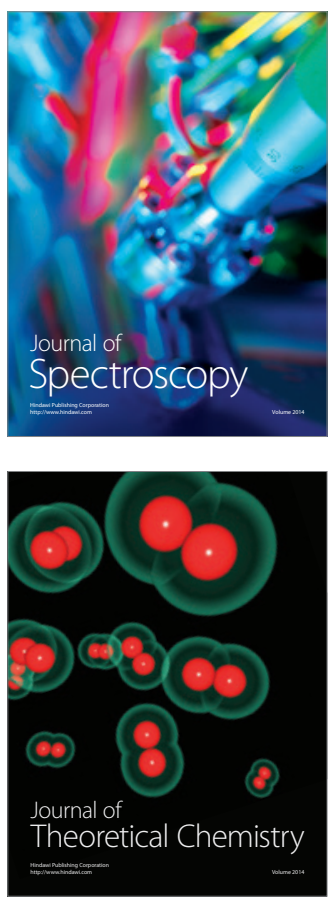
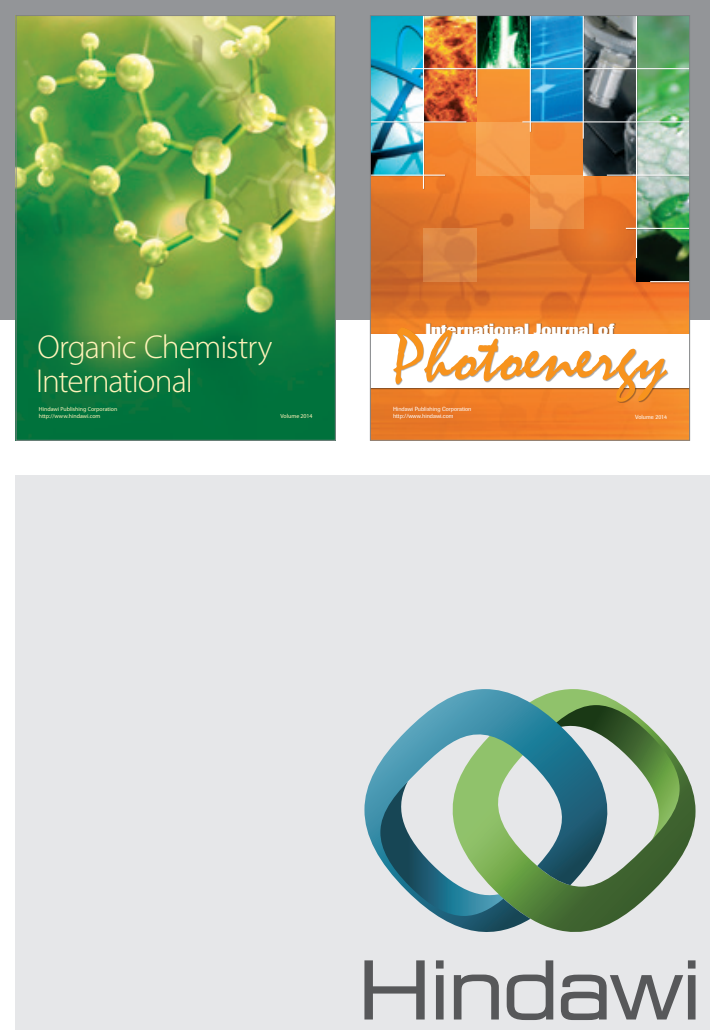

Submit your manuscripts at

http://www.hindawi.com
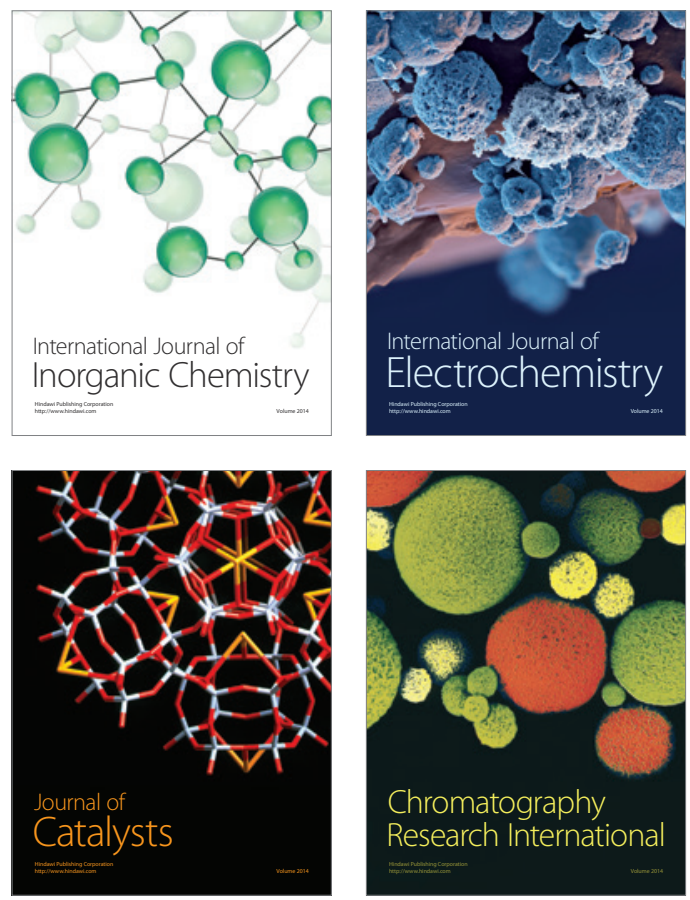
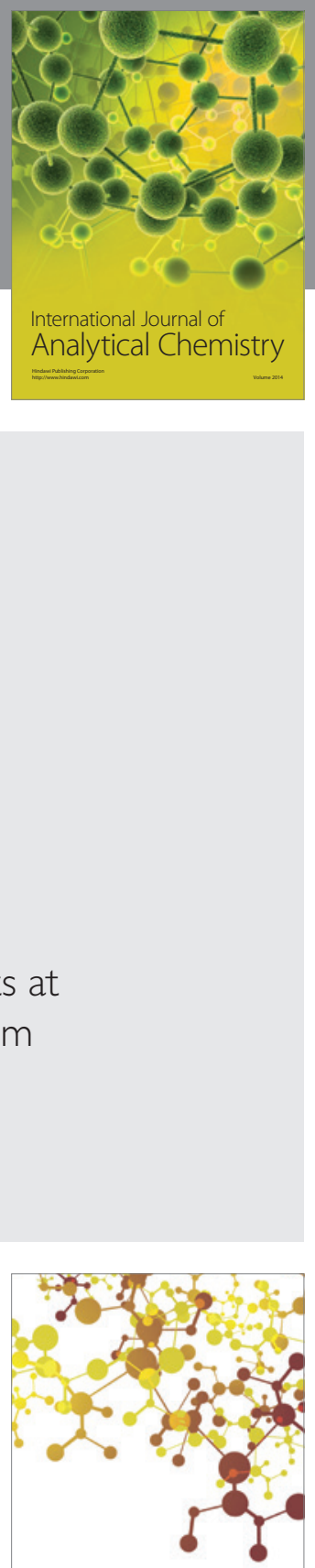

Journal of

Applied Chemistry
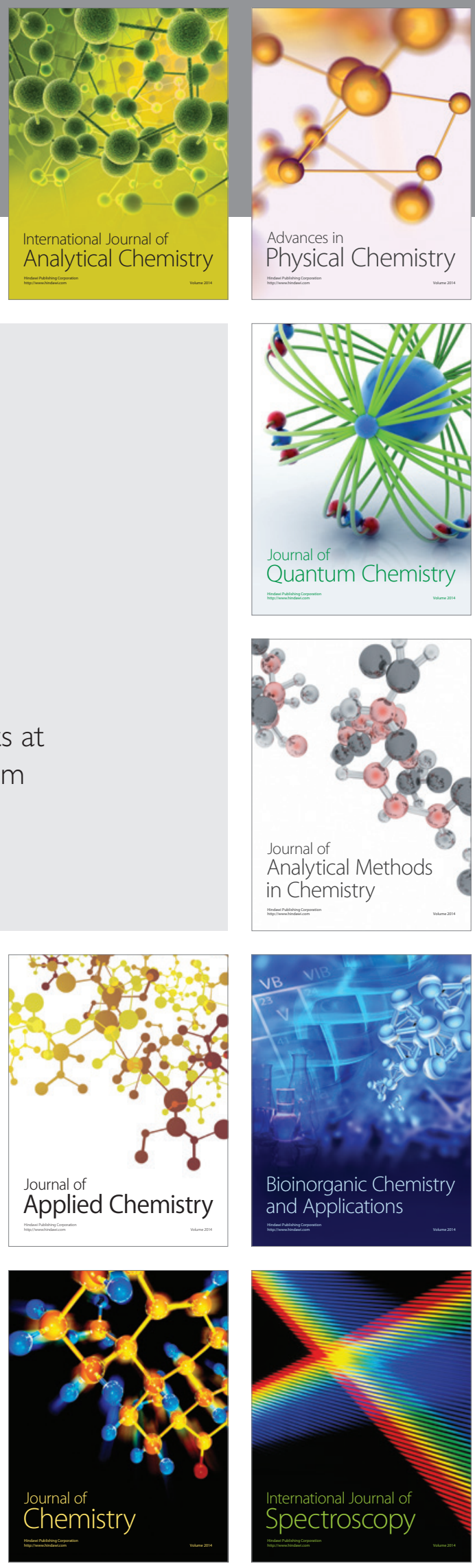